\title{
Factors influencing the knowledge and attitude of nurses towards adverse drug reaction reporting in a teaching hospital
}

\author{
Marya Ahsan $^{1 *}$, Ayaz K. Mallick ${ }^{2}$
}

${ }^{1}$ Department of Pharmacology, ${ }^{2}$ Department of Biochemistry, Rohilkhand Medical College and Hospital, Bareilly, Uttar Pradesh, India

Received: 15 March 2017 Accepted: 06 April 2017

*Correspondence to:

Dr. Marya Ahsan,

Email:

marya_ahsan@yahoo.co.in

Copyright: () the author(s), publisher and licensee Medip Academy. This is an openaccess article distributed under the terms of the Creative Commons Attribution NonCommercial License, which permits unrestricted noncommercial use, distribution, and reproduction in any medium, provided the original work is properly cited.

\section{ABSTRACT}

Background: Adverse Drug Reactions (ADR) are common in hospitalized patients. Nursing staff spends most time in patient care placing them at a key it position to recognize ADRs at the earliest. However, ADR reporting practices among nurses is very poor. We conducted this study to identify the factors affecting knowledge and attitude of nurses in a teaching hospital towards ADR reporting.

Methods: A pre-tested and validated questionnaire was used. Correct responses in the knowledge section were awarded one mark and incorrect responses were given zero. Based on responses to attitude questions on a 5-point Likert scale, best attitude was scored five and least preferred attitude was given one point. Total knowledge and attitude scores were analyzed with regards to age, gender, educational qualification, average weekly working hours, total working experience in years and past experience with ADRs and ADR reporting. Knowledge scores were also correlated with attitude scores.

Results: Knowledge level was poor with $48.29 \pm 23.85 \%$ average score while attitude of the respondents was reasonable with $65.69 \pm 10.05 \%$ average scores. The knowledge scores and attitude scores of BSc degree holders was higher than GNMs and ANMs ( $<<0.001)$. Those who had independently identified an ADR had higher knowledge scores $(\mathrm{p}<0.01)$ and more positive attitude $(\mathrm{p}<0.001)$. Attitude scores also had a significantly strong correlation with knowledge level of the respondents $(r=0.72)$.

Conclusions: Knowledge about ADR reporting is the most important factor determining the attitude towards ADR reporting. Increasing awareness would be pivotal in changing attitude and thus, improving reporting rates.

Keywords: ADR reporting, Attitude, Knowledge, Nurses

\section{INTRODUCTION}

Harmful effects of drugs have been known to man ever since it was used for treatment of their ailments. These adverse reactions to drugs had been described by Mathew Prior in his poem as 'Cured yesterday of my disease, I died last night of my physician'. 'The WHO defined adverse drug reaction (ADR) in 1972 as 'a response to a drug which is noxious and unintended, and which occurs at doses normally used in man for the prophylaxis, diagnosis or therapy of disease or for the modification of physiological functions. ${ }^{2}$ ADRs are one of the leading causes of morbidity and mortality and also add to the treatment expenditure. ${ }^{3-5}$ In a developing country like India, the additional cost of managing an ADR is wasted expenditure. $^{6}$
Pharmacovigilance is a tool to detect, assess and prevent ADRs and ensure safer drugs to the patients. ${ }^{7}$ Every country has its own ADR detecting programme, but very few ADRs are actually reported. ${ }^{8}$ India is not new to ADR monitoring and many programmes have been launched since 1980s. ${ }^{9}$ In spite of these measures, ADR reporting rate in India is as low as opposed to the global counterpart of 5\%. ${ }^{10-12}$ To address the lacunae in generating sufficient contribution to the global safety database, the Pharmacovigilance Programme of India (PvPI) was launched in July 2010 under which all healthcare professionals and non-healthcare professionals including consumers can report suspected ADRs. ${ }^{13}$

ADRs are frequent in hospitals accounting for $1-12 \%$ of all hospital admissions. ${ }^{14-18}$ It is estimated that $2-80 \%$ of 
hospitalized patients experience an ADR during their stay. ${ }^{3,14,19}$ Nurses constitute a potentially valuable source for voluntary ADR reports in hospitals where ADR is more likely to be severe. ${ }^{19}$ If nurses are actively involved in pharmacovigilance, ADRs in hospitals can be detected early and reported more accurately. Thus, we conducted this study to identify the factors affecting knowledge and attitude of nurses of a teaching hospital in North India towards ADR reporting.

\section{METHODS}

The study was conducted as a cross-sectional questionnaire based study among nursing staff in a teaching hospital in North India. Institutional Ethical Committee clearance was taken before the study. Participants also gave informed consent before participation. All the nursing staff working in the teaching hospital during Jan-March 2016 were enrolled for the study.

The nursing personnel were approached personally by the principal investigator and were given the questionnaires. Completed questionnaires were collected in the same sitting. Those who were unable to return the questionnaire in the same sitting for any reason were excluded from the study.

Pre-tested and validated questionnaire was used as tool of investigation. The questionnaire format was adapted from earlier studies. ${ }^{11,12,20}$ It was divided into 3 sections A, B and C. Section A enquired about the variables related to reporting that could influence the knowledge and attitude towards ADR reporting such as age, gender, qualification, years of experience, average working hours per week, any training in ADR reporting and past experience with ADR reporting. Section B and C consisted of 8 items each. While Section B was designed to evaluate the knowledge about ADR reporting, section $\mathrm{C}$ was related to the attitude towards ADR reporting. Knowledge related questions in section $\mathrm{B}$ were given as multiple choice questions. Correct responses were awarded one mark and incorrect responses were marked zero.

Total score in section B was calculated as the sum of individual response scores. The total scores in knowledge section were evaluated as an additional variable influencing attitude. Attitude related questions were evaluated on a five-point Likert scale with the best attitude given five marks and the least preferred attitude given one mark. Total marks in section $\mathrm{C}$ was calculated by adding up marks of each item.

Statistical Package for Social Science version 23.0 was used to analyze the completed questionnaires. Independent t-test, one way ANOVA for groups and correlation statistics were applied. $\mathrm{P}$ value $<0.05$ was considered as cut-off for statistical significance.

\section{RESULTS}

A total of 250 questionnaires were distributed and 210 questionnaires were collected. Thirteen questionnaires were excluded as they did not have sufficient responses. The total response rate was $78.8 \%$. The average knowledge score of the participants was $48.29 \pm 23.85 \%$ and the average attitude score was $65.69 \pm 10.05 \%$.

Though 26 nurses had independently identified an ADR at least once, none had ever reported them to Pharmacovigilance Programme of India (PvPI). Also none of the nurses in our study had received any training in ADR reporting.

As shown in Table 1, $72.6 \%$ of the participants could correctly define ADR and $59.4 \%$ knew the definition of pharmacovigilance. Knowledge about other aspects of ADR reporting was poor, with only $18.8 \%$ correctly identifying the location of the National Coordinating Centre at Indian Pharmacopeia Commission (Ghaziabad) and only $25.9 \%$ knew where to send the report. $40 \%$ of the nurses in our study did not know that they too could report ADRs (Table 1).

Table 1: Response of the participants in the knowledge Section $(n=197)$.

\begin{tabular}{|lll|}
\hline Questions & $\begin{array}{l}\text { Right } \\
\text { response }\end{array}$ & $\begin{array}{l}\text { Wrong } \\
\text { response }\end{array}$ \\
\hline Definition of ADR & $143(72.6 \%)$ & $54(27.4 \%)$ \\
\hline $\begin{array}{l}\text { Definition of } \\
\text { Pharmacovigilance }\end{array}$ & $117(59.4 \%)$ & $80(40.6 \%)$ \\
\hline $\begin{array}{l}\text { Where is the National } \\
\text { Coordinating Centre of } \\
\text { PvPI? }\end{array}$ & $37(18.8 \%)$ & $160(81.2 \%)$ \\
\hline $\begin{array}{l}\text { What are the different } \\
\text { modes of reporting an } \\
\text { ADR? }\end{array}$ & $81(41.1 \%)$ & $116(58.9 \%)$ \\
\hline $\begin{array}{l}\text { ADR reporting is to be } \\
\text { done for which drugs? }\end{array}$ & $86(43.7 \%)$ & $111(56.3 \%)$ \\
\hline $\begin{array}{l}\text { What types of ADRs } \\
\text { are to be reported? }\end{array}$ & $128(65 \%)$ & $69(35 \%)$ \\
\hline $\begin{array}{l}\text { Who can report? } \\
\text { Where is the report } \\
\text { sent? }\end{array}$ & $118(59.9 \%)$ & $79(40.1 \%)$ \\
\hline
\end{tabular}

Also shown in Table 2 is that $54.3 \%$ nurses felt that ADR reporting is a professional obligation and $43.66 \%$ agreed that ADR reporting is important for patient safety.

Almost $90 \%$ of the nurses agreed to report an ADR in the future. The discouraging attitude of the nurses identified in our study to ADR reporting were demand of financial incentives for reporting by $84 \%$ of nurses and lack of time was considered a hindering factor by $76 \%$ of nurses (Table 2). 
Table 2: Response of the participants in the attitude section $(n=197)$.

\begin{tabular}{|llllll|}
\hline Question & $\begin{array}{l}\text { Strongly } \\
\text { agree }\end{array}$ & Agree & Can’t say & Disagree & Strongly disagree \\
\hline $\begin{array}{l}\text { ADR reporting is a } \\
\text { professional obligation }\end{array}$ & $29(14.72 \%)$ & $78(39.59 \%)$ & $64(32.49 \%)$ & $19(9.64 \%)$ & $7(3.55 \%)$ \\
\hline $\begin{array}{l}\text { ADR reporting is important } \\
\text { for patient safety }\end{array}$ & $26(13.2 \%)$ & $60(30.46 \%)$ & $92(46.7 \%)$ & $13(6.6 \%)$ & $6(3.05 \%)$ \\
\hline $\begin{array}{l}\text { Single ADR report will also } \\
\text { make a difference }\end{array}$ & $29(14.72 \%)$ & $90(45.69 \%)$ & $55(27.92 \%)$ & $18(9.14 \%)$ & $5(2.54 \%)$ \\
\hline $\begin{array}{l}\text { Do you fear legal action for } \\
\text { reporting }\end{array}$ & $34(17.26 \%)$ & $31(15.74 \%)$ & $85(43.15 \%)$ & $26(13.2 \%)$ & $21(10.66 \%)$ \\
$\begin{array}{l}\text { Should you get financial } \\
\text { incentives for reporting }\end{array}$ & $100(50.76 \%)$ & $66(33.5 \%)$ & $5(2.54 \%)$ & $26(13.2 \%)$ & 0 \\
\hline $\begin{array}{l}\text { Lack of time prevents you } \\
\text { from reporting }\end{array}$ & $24(12.18 \%)$ & $125(63.45 \%)$ & $13(6.6 \%)$ & $35(17.77 \%)$ & 0 \\
\hline $\begin{array}{l}\text { Will you attend a training } \\
\text { course/CME on ADR } \\
\text { reporting }\end{array}$ & $113(57.36 \%)$ & $60(30.36 \%)$ & $23(11.68 \%)$ & $1(0.5 \%)$ & 0 \\
\hline Will you report an ADR & $87(44.16 \%)$ & $89(45.18 \%)$ & $20(10.15 \%)$ & $1(0.5 \%)$ & 0 \\
\hline
\end{tabular}

As illustrated in Figure 1 and 2, the knowledge scores and attitude scores of males $(n=8)$ were higher than females $(n=189)$ but the difference was not statistically significant. Among the respondents, $13.2 \%$ had a BSc degree in nursing, $66.5 \%$ were GNMs and $20.3 \%$ were ANMs. Statistically significant difference was seen in the knowledge scores among different qualified respondents $(p<0.001)$. The attitude of higher degree holders was also significantly better $(\mathrm{p}<0.001)$. Those who had identified an ADR independently in the past $(n=26)$ also had higher knowledge scores than those who had not $(n=171)$ $(\mathrm{p}<0.01)$. Their attitude towards ADR reporting was also better $(\mathrm{p}<0.001)$.

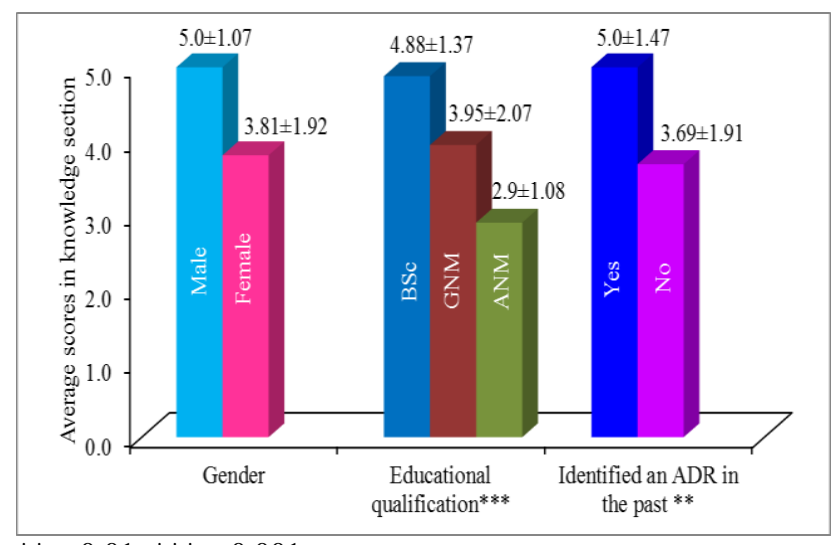

$* * \mathrm{p}<0.01, * * * \mathrm{p}<0.001$

Figure 1: Average Scores in Knowledge Section based on gender, education qualification and past experience with ADR.

After applying correlation statistics, there was a significantly strong correlation $(r=0.72)$ between the knowledge scores of the participant and their attitude towards ADR reporting ( $\mathrm{p}<0.001)$ (Table 3 and Figure 3 ).

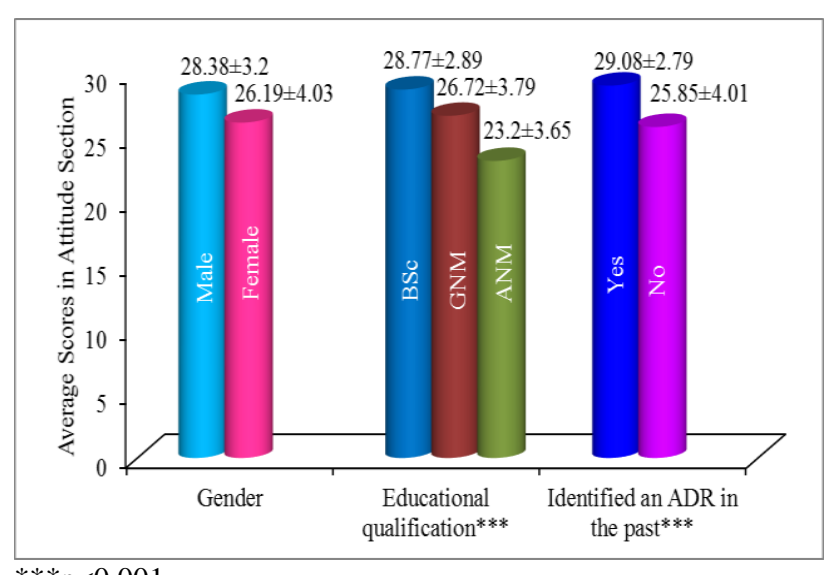

Figure 2: Average scores in attitude section based on gender, educational qualification and past experience with an ADR.

Table 3: Correlation of continuous variables with Knowledge and Attitude scores.

\begin{tabular}{|c|c|c|c|}
\hline \multirow{2}{*}{ Variable } & \multirow{2}{*}{$\begin{array}{l}\text { A verage } \\
(n=197)\end{array}$} & \multicolumn{2}{|c|}{$\begin{array}{l}\text { Pearson Correlation } \\
\text { factor ' } r \text { ' with }\end{array}$} \\
\hline & & $\begin{array}{l}\text { Knowledge } \\
\text { scores }\end{array}$ & $\begin{array}{l}\text { Attitude } \\
\text { scores }\end{array}$ \\
\hline Age in years & $30.03 \pm 3.41$ & 0.12 & $0.16^{*}$ \\
\hline $\begin{array}{l}\text { Working hours/ } \\
\text { week }\end{array}$ & $49.23 \pm 2.68$ & 0.03 & 0.05 \\
\hline $\begin{array}{l}\text { Working } \\
\text { experience in } \\
\text { years }\end{array}$ & $5.38 \pm 3.37$ & $0.14^{*}$ & $0.18 * *$ \\
\hline $\begin{array}{l}\text { Total knowledge } \\
\text { scores } \\
\text { percentage }\end{array}$ & $48.29 \pm 23.85$ & - & $0.72 * * *$ \\
\hline
\end{tabular}


Also shown in Table 3 is that the association between attitude towards ADR reporting and age $(r=0.16)$, attitude towards ADR reporting and working experience of the participants $(r=0.18)$ was significant, this was weak.

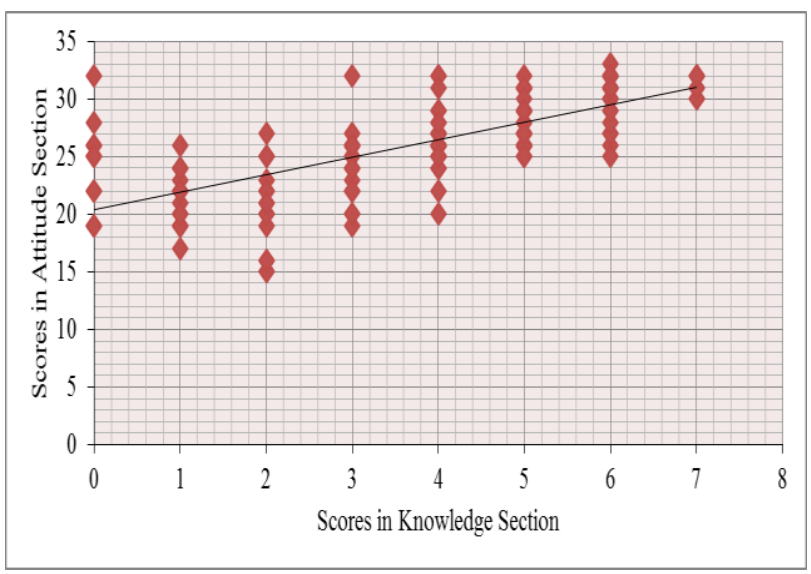

$\mathrm{r}=0.72, \mathrm{p}<0.001$

\section{Figure 3: Correlation of attitude scores of the respondents with their knowledge scores.}

\section{DISCUSSION}

Adverse drug reactions are common in hospitalized patients. Health care professionals working in the hospital can detect any untoward reaction to drugs at the earliest and report the same to the ADR monitoring programmes. Nurses are involved in drug administration and record maintenance. Moreover, they are the ones who interact frequently with the patient, thus placing them at a key position to recognize any adverse drug reaction. Keeping this in view, the Pharmacovigilance Programme of India allows nurses to report adverse drug reactions. However, ADR reporting practices among nurses is very poor as demonstrated from earlier studies..$^{20-22}$ In our hospital, none of the nurses had ever reported an ADR even though 26 nurses had identified ADRs in the past.

The average level of knowledge in our study was $48.29 \%$ which was lower than the knowledge level of nurses in South India $(56.4 \%) .{ }^{21}$ Majority of the nurses in our study understood the term adverse drug reactions and pharmacovigilance. This result was considerably better than study done among nurses in Tehran. ${ }^{20}$ However, the knowledge of other aspects of ADR reporting was inadequate among the nurses. Similar finding was demonstrated by other studies among nurses..$^{20,21}$

The attitude level of the nurses in our study was $65.69 \%$. This result was in line with other studies. ${ }^{21}$ Majority of the nurses believed that ADR reporting is a professional obligation and important for patient safety. The most important discouraging factor in the attitude of the nurses towards ADR was demand for financial incentives and lack of time being blamed for paucity of reports. However, the fact that $90 \%$ of the nurses in our study were agreeing to report an $\mathrm{ADR}$ in the future was encouraging. Moreover, $88 \%$ of nurses demonstrated willingness to attend CMEs and training on ADR reporting was encouraging. Physicians in teaching hospitals had also identified hands-on-training to improve ADR reporting practices. ${ }^{23}$

On analyzing the factors influencing knowledge and attitude, we found that the knowledge and attitude of nurses was not affected by their gender. Though the male nurses scored higher in knowledge about ADR reporting than the female nurses, this difference was not statistically significant. The male nurses also had better scores in their attitude towards ADR reporting, but again it was not statistically significant. The higher scores of the male nurses can also be explained by the fact that all the male nurses in our study had a higher educational qualification (BSc nursing degree), which is an independent factor affecting knowledge and attitude in our study.

The knowledge of ADR reporting was significantly influenced by the educational qualification of nurse. Those with a Bachelor's degree in nursing scored better than GNMs and ANMs. Though there was a small difference in knowledge scores between the BSc degree holders and GNMs, this was statistically significant. Similar difference was seen between GNMs and ANMs. The difference in knowledge levels was almost doubled between the BSc nurses and ANMs ( $\mathrm{p}<0.001)$.

Attitude towards ADR reporting was also significantly affected by the educational qualification of the respondents. The attitude towards ADR reporting improved significantly at each level with increasing qualification of the nurses. Those with a bachelor's degree demonstrated the best attitude towards ADR reporting. Poorest attitude in our study was among ANMs.

Better training and higher qualification of the nurses impacted favorably both the knowledge about ADR reporting and also the attitude towards ADR reporting. Study done among pharmacists in Western China also showed that higher professional title was an important determinant of knowledge and attitude of pharmacists. ${ }^{24}$ However in our study, it did not translate into ADR reporting practices as none of the $\mathrm{BSc}$ nurses had ever reported an ADR. This points to need for more training and motivation.

In our study, we saw that nurses who had independently identified an ADR in their past experience had significantly higher knowledge levels and also displayed better attitude towards ADR reporting in comparison to those who had no past experience with ADRs. However, the fact that only $13.2 \%$ of the nurses had identified an ADR in their past experience points to a lacuna in the training of nurses with regards to adverse drug reactions. This result can also be explained vice-versa as, those 
having better knowledge of adverse reactions to drugs were more able to identify ADRs correctly.

In our study we did not find any influence of age of the respondents or the experience of the respondents on the knowledge of ADR reporting. However, attitude towards ADR reporting was better with increasing age and increasing working experience. Though the correlation was statistically significant, it was weak.

The impact of knowledge about ADR reporting was the most important determinant of attitude towards ADR reporting in our study. There was a strong positive correlation between the knowledge and attitude scores in our study. This finding was highly significant. This fact is also reiterated in the finding that those with a higher qualification have better knowledge and thus better attitude scores also.

Thus, the most important intervention is to improve the knowledge of health professionals about ADR reporting through training programmes and CMEs. Most of the participants in our study were willing to attend such programmes. Better knowledge would translate into better attitude and further improved ADR reporting practices.

\section{CONCLUSION}

Knowledge about ADR reporting was poor among the nurses while their attitude towards reporting was just reasonable. We found that knowledge about ADR reporting is the most important factor determining the attitude of the nurse towards ADR reporting. Those with a higher qualification demonstrated better knowledge levels which translated into favorable attitude. Steps directed towards increasing the awareness would be pivotal in changing attitude and thus increasing ADR reporting rates.

Funding: No funding sources

Conflict of interest: None declared

Ethical approval: The study was approved by the Institutional Ethics Committee

\section{REFERENCES}

1. Bullard J. Physical Fitness: Who Needs It? Can Fam Physician. 1980;26:477-9.

2. World Health Organization. International drug monitoring: the role of national centres. WHO technical report series no. 498. Geneva, Switzerland: World Health Organization; 1972. Available from: http://www.who-umc.org/graphics/24756.pdf

3. Pirmohamed M, James S, Meakin S, Green C, Scott AK, Walley TJ et al. Adverse drug reactions as cause of admission to hospital: prospective analysis of 18820 patients. BMJ. 2004;329:15-9.
4. Miller GC, Britt HC, Valenti L. Adverse drug events in general practice patients in Australia. Med J Aust 2006;184(6):321-4.

5. Lundkvist J, Jonsson B. Pharmacoeconomics of adverse drug reactions. Fundam Clin Pharmacol. 2004;18(3):275-80.

6. Ramesh M, Pandit J, Parthasarathi G. Adverse drug reactions in a south Indian hospital--their severity and cost involved. Pharmacoepidemiol Drug Saf. 2003;12(8):687-92.

7. World Health Organization. WHO pharmacovigilance Indicators: A Practical Manual for the Assessment of Pharmacovigilance Systems. Available

from: http://apps.who.int/iris/bitstream/10665/186642/1/97 89241508254_eng.pdf?ua=1.

8. Hazell L, Shakir SA. Under-reporting of adverse drug reactions: a systematic review. Drug Saf. 2006;29(5):385-96.

9. Baniasadi S, Fahimi F, Shalviri G. Developing an adverse drug reaction reporting system at a teaching hospital. Basic Clin Pharmacol Toxicol. 2008;102(4):408-11.

10. Indian Pharmaceutical Industries 2010: Strategies in a Changing World. Available from: http://www.thepharmaletter.com/article/indianpharmaceutical-industry-new-strategies-in-achanging-worldwww.espicom.com.

11. Elizabeth ST, Kia RA, Yagnik RM, Nagaraju K. Knowledge, attitude and skills of nurses of Delhi towards adverse drug reaction reporting. Indian $\mathbf{J}$ Pharm Pract. 2012;5:45-51.

12. Desai CK, Iyer G, Panchal J, Shah S, Dikshit RK. An evaluation of knowledge, attitude, and practice of adverse drug reaction reporting among prescribers at a tertiary care hospital. Perspect Clin Res. 2011;2(4):129-36

13. Suke SG, Kosta P, Negi H. Role of Pharmacovigilance in India: An overview. Online J Public Health Inform. 2015;7(2):e223.

14. Bouvy JC, De Bruin ML, Koopmanschap MA. Epidemiology of Adverse Drug Reactions in Europe: A Review of Recent Observational Studies. Drug Saf. 2015;38(5):437-53.

15. van der Hooft CS, Dieleman JP, Siemes C, Aarnoudse AJ, Verhamme KM, Stricker BH, et al. Adverse drug reaction-related hospitalisations: a population-based cohort study. Pharmacoepidemiol Drug Saf. 2008;17(4):365-71.

16. Kongkaew C, Noyce PR, Ashcroft DM. Hospital admissions associated with adverse drug reactions: a systematic review of prospective observational studies. Ann Pharmacother. 2008;42(7):1017-25.

17. Stausberg. International prevalence of adverse drug events in hospitals: an analysis of routine data from England, Germany, and the USA. BMC Health Serv Res. 2014;14:125.

18. Bond CA, Raehl CL. Adverse drugs reactions in United States hospitals. Pharmacotherapy. 2006;26:601-8. 
19. Sriram S, Ghasemi A, Ramasamy R. Prevalence of adverse drug reactions at a private tertiary care hospital in south India. $\mathbf{J}$ Res in Med Sci. 2011;16(1):16-25.

20. Hanafi S, Torkamandi H, Hayatshahi A, Gholami K, Javadi M. Knowledge, attitudes and practice of nurse regarding adverse drug reaction reporting. Iran J Nurs Midwifery Res. 2012;17(1):21-5.

21. Scandashree K, Kumar BP, Udaykumar P, Thomas TM. Knowledge, attitude, and practice of adverse drug reaction reporting among nurses in a South Indian tertiary health-care center. Natl J Physiol Pharm Pharmacol 2017;7(2):143-6.

22. Hall M, McCormack P, Arthurs N, Feely J. The spontaneous reporting of adverse drug reactions by nurses. Br J Clin Pharmacol. 1995;40(2):173-5.

23. Vallano A, Cereza G, Pedrds C, Agusti A, Danes I, Aguilera C, et al. Obstacles and solutions for spontaneous reporting of adverse drug reactions in the hospital. Br J Clin Pharmacol. 2005;60(6):653-8.

24. Liu J, Zhou Z, Yang S, Feng B, Zhao J, Liu H et al. Factors that affect adverse drug reactions reporting among hospital pharmacists in Western China. Int $\mathbf{J}$ Clin Pharm. 2015;37(3):457-64.

Cite this article as: Ahsan M, Mallick AK. Factors influencing the knowledge and attitude of nurses towards adverse drug reaction reporting in a teaching hospital. Int J Basic Clin Pharmacol 2017;6:1215-20. 